\title{
LARYNGOLOGY
}

\section{A one-year time frame for voice prosthesis management. What should the physician expect? Is it an overrated job?}

\author{
Finestra di un anno sulla gestione di pazienti con protesi fonatoria. \\ È un carico clinico sovrastimato?
}

\author{
Claudio Parrilla', Ylenia Longobardi', Gaetano Paludetti', Maria Elisabetta Marenda'1, Lucia D'Alatri', Francesco Bussu',3, \\ Emanuele Scarano ${ }^{3}$, Jacopo Galli ${ }^{1}$ \\ ${ }^{1}$ Fondazione Policlinico Universitario A. Gemelli IRCCS, Università Cattolica del Sacro Cuore, Istituto di Otorinolaringoiatria, Rome, Italy; \\ ${ }^{2}$ Otolaryngology Division AOU, Sassari, Italy; ${ }^{3}$ Università Cattolica del Sacro Cuore, Istituto di Otorinolaringoiatria, Rome, Italy
}

\begin{abstract}
SUMMARY
Management of late complications represents the main reason for reluctance in using voice prosthesis rehabilitation. The aim of this paper is to report our experience by describing the one-year management of a large cohort of patients in order to clarify how demanding management is in terms of burden on clinicians. Between June 2017 and June 2018, each access made at the Otolaryngology Clinic of our Institute for issues related to prosthesis by 70 laryngectomised patients rehabilitated by voice prosthesis was registered in a specific database. A review of the data provided information on the incidence, management and outcomes of adverse events encountered during the selected time frame. In addition, a T test was used to evaluate the differences between irradiated and non-irradiated patients and between primary and secondary tracheo-oesophageal-puncture. Leakage through the prosthesis was the most common cause for access (51.86\%). The median number of accesses per patient per year was 3.47. The speech therapist autonomously managed $18.1 \%$ of accesses. The median number of accesses per patient per year needing a physician was 2.84 . The median lifetime of the prosthesis was 4.85 months. Radiotherapy or modality (primary or secondary) of the puncture did not influence the number of accesses per year or the prosthesis lifetime. This retrospective analysis of results highlighted the most frequent issues and the most effective measures to deal with them, which allowed us to define a systematic algorithm to standardise and ease long-term outpatient management.
\end{abstract}

KEY WORDS: total laryngectomy, voice prosthesis, post-laryngectomy, rehabilitation, multidisciplinary

\section{RIASSUNTO}

La gestione delle complicanze tardive rappresenta il motivo principale della riluttanza nell'uso della riabilitazione con protesi fonatoria dopo laringectomia totale. Lo scopo del presente lavoro è descrivere un anno di gestione di un'ampia coorte di pazienti, al fine di chiarire quanto impegnativo sia il management in termini di carico lavorativo per i clinici dedicati. Nel periodo compreso tra giugno 2017 e giugno 2018, ogni accesso effettuato, presso la Clinica di Otorinolaringoiatria del nostro Istituto, da 70 pazienti laringectomizzati riabilitati con protesi fonatoria per problematiche legate al dispositivo protesico, è stato registrato su uno specifico database. L'analisi dei dati ha fornito informazioni sull' incidenza, la gestione e gli outcomes relativi a tutti gli eventi avversi riscontrati durante il periodo preso in esame. Al fine di valutare le differenze tra pazienti irradiati e non irradiati e pazienti sottoposti a posizionamento simultaneo e sequenziale/ritardato è stato, inoltre, utilizzato il test $T$ di Student. Il leakage intravalvolare è stata la causa di accesso più frequente $(51,86 \%)$. Il numero medio di accessi per paziente per anno è stato pari a 3,47. La logopedista ha gestito autonomamente il 18,1\% degli accessi. Di conseguenza, il numero medio di accessi per paziente per anno che hanno necessitato di visita medica è stato pari a 2,84. La durata media del dispositivo protesico è stata pari a 4,85 mesi. La radioterapia o la tecnica di posizionamento utilizzata (simultanea o sequenziale/ritardata) non ha influen-
Received: December 30, 2019

Accepted: April 24, 2020

Correspondence

Ylenia Longobardi

Otolaryngology Head and Neck Surgery Department, Catholic University of the Sacred Heart,

1.go F. Vito 1, 00168 Rome, Italy

E-mail: ylenia.longobardi@guest.policlinicogemelli.it

Funding

None

Conflict of interest

The Authors declare no conflict of interest.

How to cite this article: Parrilla C, Longobardi Y, Paludetti G, et al. A one-year time frame for voice prosthesis management. What should the physician expect? Is it an overrated job? Acta Otorhinolaryngol Ital 2020;40:270-276. https://doi. org/10.14639/0392-100X-N0587

(C) Società Italiana di Otorinolaringoiatria e Chirurgia Cervico-Facciale

\section{c) (i) $\$$}

This is an open access article distributed in accordance with the CC-BY-NC-ND (Creative Commons Attribution-NonCommercial-NoDerivatives 4.0 International) license. The article can be used by giving appropriate credit and mentioning the license, but only for non-commercial purposes and only in the original version. For further information: https:// creativecommons.org/licenses/by-nc-nd/4.0/deed.en 
zato il numero di accessi per anno né la durata della protesi fonatoria. L'analisi retrospettiva dei risultati ha evidenziato le problematiche più frequenti e le misure più efficaci per affrontarle, permettendo la creazione di un algoritmo sistematico che agevoli e standardizzi il management a lungo termine di questi pazienti.

PAROLE CHIAVE: laringectomia totale, protesi fonatoria, post-laringectomia, riabilitazione, multidisciplinare

\section{Introduction}

Over the last 30 years, trachea-oesophageal speech (TES) has become the gold standard for rehabilitation following total laryngectomy ${ }^{1}$ thanks to a more natural sounding voice, superior voice quality, shorter rehabilitation time ${ }^{2,3}$ and a higher success rate (ranging from 60 to $90 \%)^{4}$ compared with other rehabilitation methods.

Generally speaking, it is recognised that four main reasons hinder the widespread use of TES: surgical complications (early complications), long-term voice prosthesis/fistula troubles (late complications), cost of devices and burden on physicians.

Early complications are in most cases "minor" (e.g. trauma to the lips/teeth, superficial mucosal lacerations), both in primary and secondary settings 5 . Major complications (e.g. oesophageal perforation) are quite rare and always related to difficult secondary puncture ${ }^{6-10}$. Diagnosis and management of early minor and major complications is beyond the scope of this paper, but the general worldwide orientation is a preference, as much as possible, for primary punctures to reduce the risk of major, life-threatening complications.

Our focus is on late complications, which could be considered unavoidable consequences of the fistula and/or of the presence of a foreign body (i.e. voice prosthesis). The management of these issues is considered time demanding, often causes anxiety in non-experienced non-specifically trained specialists and, in the real world, it represents the main obstacle for many physicians to voice prosthesis rehabilitation. Voice prosthesis patients are, in fact, notoriously characterised by much more frequent visits to healthcare professionals than oesophageal speakers. Some late sequelae are easy to manage, whereas others may challenge even the most experienced clinician ${ }^{11}$.

The lifetime of voice prostheses is one of the limitations of TES, representing the need for ongoing replacement of the valve ${ }^{12}$. The main cause $(80 \%)$ for replacement of an indwelling device is internal leakage (intravalvular leakage) due to the contamination by a biofilm of bacteria and yeasts that renders the valve incompetent ${ }^{13,14}$.

Other reasons for device replacement/adjustment are leakage around the device, fistula-related problems including formation of granulation tissue, or infection ${ }^{15,16}$. Leakage around the prosthesis is often due to the gradual thinning of the tracheo-oesophageal-puncture site (TEP), and consequent shortening of the prosthesis is a natural course of events, representing about $10 \%$ of all voice prosthesis substitutions ${ }^{17-21}$.

In addition, functional issues (immediate or delayed aphonia or dysphonia) represent a frequent problem that brings the patient to the hospital to be treated accordingly 22,23 .

The aim of this paper is to analyse a 1-year window of troubleshooting in a multidisciplinary setting for a large cohort of voice prosthesis rehabilitated patients, to quantify how demanding management is and to propose an algorithm that is useful to minimise the time and burden for dedicated clinicians.

\section{Materials and methods}

Between June 2017 and June 2018, 70 voice prosthesis patients made 243 accesses at the Otolaryngology Clinic and Phoniatric Unit of our Institute for issues related to their prosthesis. In our centre, there is a dedicated team for management of voice prosthesis patients consisting of 2 ENT surgeons and 3 speech therapists. Each team member has specific training and is able to perform patient visits to evaluate the voice prosthesis, fistula and peristomal tissues. The median age was $65.12 \pm 6.53$ years (range 5480 years). All patients had undergone total laryngectomy with bilateral neck dissection and TEP for voice restoration. All patients included in the study had undergone primary closure of the pharynx, except for three free flap non-tubed reconstructions (2-anterolateral thigh and 1 forearm) in the salvage setting after concomitant radio-chemotherapy.

Forty-six patients had been subjected to primary $(\mathrm{n}=12 / 26.08 \%)$ or adjuvant $(\mathrm{n}=34 / 73.91 \%)$ radiotherapy. In 28 of 70 patients (40\%), a secondary TEP was chosen.

The interval between total laryngectomy and prosthesis implantation varied from 2 to 108 months $(25.38 \pm 27.55)$. All patients were primarily trained by the speech therapist in the use and maintenance of the fistula and prosthesis. Speech therapy rehabilitation began on the $10^{\text {th }}-12^{\text {th }}$ postoperative day for patients undergoing primary TEP, after the removal of the nasogastric tube. For patients with secondary TEP, rehabilitation started 24 hours after the operation. Speech therapy provided coordination exercises, which included breath and digital stoma occlusion, production of vocalisations, bi-syllabic and polysyllabic words, automatic series and sentences with increasing 
length. Subsequently, patients worked on the production of exclamatory or interrogative sentences, reading short passages and conversations. Finally, specific training was carried out to improve the control of rhythm and modulation and intensity variations. Speech therapy had variable timing based on each individual case (from 10 to 20 sessions, with a median of 12 sessions). No patient ever used the Electrolarynx.

Since June $1^{\text {st }}, 2017$, each access was registered in a specific database. A review of these medical records provided information on the incidence, management and outcomes of adverse events encountered during the selected time frame (1 June 2017 - 1 June 2018). The data were managed as hand-entry during routine practice and the records were then interrogated as a chart/case review. The appointed person for managing this data was speech therapist.

Data used were retrospectively gathered from existing data sources. Approval from the Local Ethics Committee was obtained.

\section{Statistical analysis}

Statistical analysis was performed using JMP software, release 7.0.1, from the SAS Institute. The $\alpha$ level was fixed at 0.05 .

Paired T test was used to evaluate the differences between patients subjected to radiotherapy vs non-irradiated patients and between primary and secondary TEP.

\section{Results}

Leakage through the prosthesis occurred in 125 accesses (51.86\% of overall accesses). In 15 of 125 internal leakages, the speech therapist resolved the issue. In 110 of 125 accesses, the physician resolved the issue. The solutions adopted are summarised in Table I.

Leakage around the prosthesis was noted in 60 accesses made by 29 of 70 patients $(24.69 \%$ of overall accesses, $41.42 \%$ of patients). On most occasions, it was due to an over-long prosthesis moving back to create a piston-effect. Before coming to medical examination, 14 cases were resolved by the speech therapist. In 46 of 60 accesses, the leakage around the prosthesis was resolved by a physician. The solutions adopted are summarised in Table II.

Some patients developed aphonia or dysphonia, immediate or delayed, showing excessive vocal effort (28 accesses, $11.52 \%$ ). The first step in the management of this problem was speech therapist evaluation, who resolved it in 10 of 28 cases. In 14 of 28 cases, the dysphonia/aphonia was resolved by a physician. Three of 14 patients were treated with chemical denervation with botulinum toxin. In 4 accesses ( 3 of which by the same patient), no attempt was successful in resolving the excessive vocal effort. The solutions used are summarised in Table III.

A growing circumferential granuloma at the tracheal wall of the puncture was observed in 16 accesses (6.58\%). In three cases, the replacement was avoided by the speech therapist. In 13 of 16 accesses, the physician resolved the issue. The solutions used are summarised in Table IV.

On 8 occasions patients presented to our clinic because $>8$ months has passed since the last substitution (3.29\%). They had no leakage or any other complication. They underwent a check-up by a speech therapist to assess the condition of the prosthesis. 2 of these 8 patients $(25 \%)$ did not require a replacement. 6 patients underwent replacement because of the poor condition of the prosthesis (75\%), in particular 1 replacement with a longer one (16.6\%), 4 with an analogous one (66.6\%) and 1 with a shorter one $(16.6 \%)$.

Two patients who ingested the voice prosthesis $(0.82 \%)$ were managed by reinsertion of the prosthesis in the operating room by secondary technique.

In two patients, granuloma formation caused voice prosthesis spontaneous extrusion $(0.82 \%)$. In one case, the prosthesis was immediately reinserted using the retrograde technique. For the remaining patient, it was necessary to replace the prothesis in the operating theatre.

Finally, we recorded a dislocated prosthesis $(0.36 \%)$ that was resolved by replacement with an analogous one and an oesophageal pocket $(0.36 \%)$ caused by overgrowth of mucosa, which was resolved by replacing the voice prosthesis with a longer one via retrograde technique.

In our series, the median number of accesses per patient

Table I. Solutions used in 125 cases of internal leakage.

\begin{tabular}{|c|c|c|}
\hline $\begin{array}{l}\text { Leakages through the prosthesis solved by speech therapist } \\
\text { Prosthesis reinsertion in leakages through the prosthesis }\end{array}$ & Deep cleaning of the prosthesis with brush, flush and aspirator & $\begin{array}{c}15 / 125(12 \%) \\
110 / 125(88 \%)\end{array}$ \\
\hline & TEP replaced with analogous one & $78 / 110(70.90 \%)$ \\
\hline & TEP replaced with shorter one & $25 / 110(22.72 \%)$ \\
\hline & TEP replaced with longer one & $3 / 110(2.72 \%)$ \\
\hline & $\begin{array}{l}\text { TEP replaced with specialised one equipped with tiny magnets } \\
\text { (ProvoxActiValve ATOS }{ }^{\circledR} \text { ) }\end{array}$ & $3 / 110(2.72 \%)$ \\
\hline & TEP replaced with longer one via retrograde technique & $1 / 110(0.90 \%)$ \\
\hline
\end{tabular}


Table II. Solutions used in 60 cases of leakage around the prosthesis.

\begin{tabular}{|c|c|c|}
\hline Leakages solved by speech therapist & Deep cleaning of the prosthesis or its relocation in situ & $14 / 60(23.33 \%)$ \\
\hline \multirow[t]{5}{*}{ Prosthesis reinsertion in leakages around the prosthesis } & & $39 / 60(65 \%)$ \\
\hline & TEP replaced with a shorter one & $22 / 39(56.41 \%)$ \\
\hline & TEP replaced with analogous one via overshooting replacement & $12 / 39(30.76 \%)$ \\
\hline & $\begin{array}{l}\text { TEP replaced with specialised one with double oesophageal flange } \\
\text { (ProvoxXtra-seal ATOS }{ }^{\circledR} \text { ) }\end{array}$ & 3/39 (7.69\%) \\
\hline & TEP replaced with a longer one & 2/39 (5.12\%) \\
\hline Leakages solved with a silicon ring & & $4 / 60(6.66 \%)$ \\
\hline Leakages solved with injectable silicone & & $3 / 60(5 \%)$ \\
\hline
\end{tabular}

Table III. Solutions used in 28 cases of aphonia/dysphonia.

\begin{tabular}{|c|c|c|}
\hline Aphonia/dysphonia solved by speech therapist & $\begin{array}{l}\text { Relaxation exercises for the cervical area, manipulation, } \\
\text { facilitating manoeuvres, change of posture, relaxed phonation } \\
\text { with pulmonary support, decrease of volume and soft voice attack }\end{array}$ & $10 / 28(35.71 \%)$ \\
\hline \multirow[t]{5}{*}{ Prosthesis reinsertion in aphonia/dysphonia } & & $11 / 28(39.28 \%)$ \\
\hline & TEP replaced with analogous one via an overshooting replacement & $6 / 11(54.54 \%)$ \\
\hline & TEP replaced with a longer one & $3 / 11(27.27 \%)$ \\
\hline & TEP replaced with a shorter one & $1 / 11(9.09 \%)$ \\
\hline & TEP replaced with a longer one via retrograde technique & $1 / 11(9.09 \%)$ \\
\hline Aphonia/dysphonia resolved with botox injection & $\begin{array}{l}60 \text { units, } 15 \text { units in } 4 \text { different points, under electromyographic } \\
\text { monitoring }\end{array}$ & $3 / 28(10.71 \%)$ \\
\hline
\end{tabular}

Table IV. Solutions used in 16 cases of granuloma.

\begin{tabular}{|c|c|c|}
\hline Issue solved by speech therapist & Relocation in situ of the prosthesis & $3 / 16(18.75 \%)$ \\
\hline \multirow[t]{4}{*}{ Prosthesis reinsertion in granuloma } & & $13 / 16(81.25 \%)$ \\
\hline & TEP replaced with analogous one via overshooting & $6 / 13(46.15 \%)$ \\
\hline & TEP replaced with a longer one & $6 / 13(46.15 \%)$ \\
\hline & TEP replaced with a longer one via retrograde technique & $1 / 13(7.69 \%)$ \\
\hline
\end{tabular}

per year was 3.47. The total number of exclusive speech therapist treatments was 44 of $243(18.1 \%)$, and in these cases the surgeon or phoniatrician did not see the patient. In the case of exclusive management by a speech therapist, the prostheses had an average lifetime of $6.07 \pm 6.49$ weeks (range 1-27.57 weeks).

Consequently, the median number of accesses per patient per year needing physician treatment was 2.84 . The median prosthesis lifetime was 4.85 months.

Student's T test showed that radiotherapy did not influence the number of accesses per year. No statistically significant difference between the irradiated group and non-irradiated group of patients was found (respectively $3.63 \pm 2.98$ vs $3.54 \pm 2.57, \mathrm{p}>0.05)$. In addition, comparison of the prosthesis lifetime between irradiated and non-irradiated patients did not show any significant difference (respectively 4.27 vs 4.88 months, $\mathrm{p}>0.05)$. The same result was found comparing the median number of accesses of patients undergoing primary puncture with patients undergoing secondary puncture. The difference was not significant (respectively, 3.13 and 4.13, $\mathrm{p}>0.05$ ). We did not analyse the differences between primary pharynx closure vs. free flap reconstruction because the latter was performed on only 3 of the 70 patients in our cohort.

\section{Discussion}

It is well demonstrated that voice prosthesis currently represents the gold standard in rehabilitation of laryngectomised patients ${ }^{24,25}$. Nevertheless, reluctance with regards to the widespread use of these devices is still present among surgeons, phoniatricians and speech therapists.

The main reason for this reticence arises from the burdensome management of late sequelae together with the cost of devices. To address the first issue, we analysed a 1-year time frame of management in a large cohort of voice prosthesis rehabilitated patients and, as a result, we developed a trouble-shooting algorithm with a technical flow chart to achieve quick and correct identification and adequate treatment of complications (Fig. 1) 

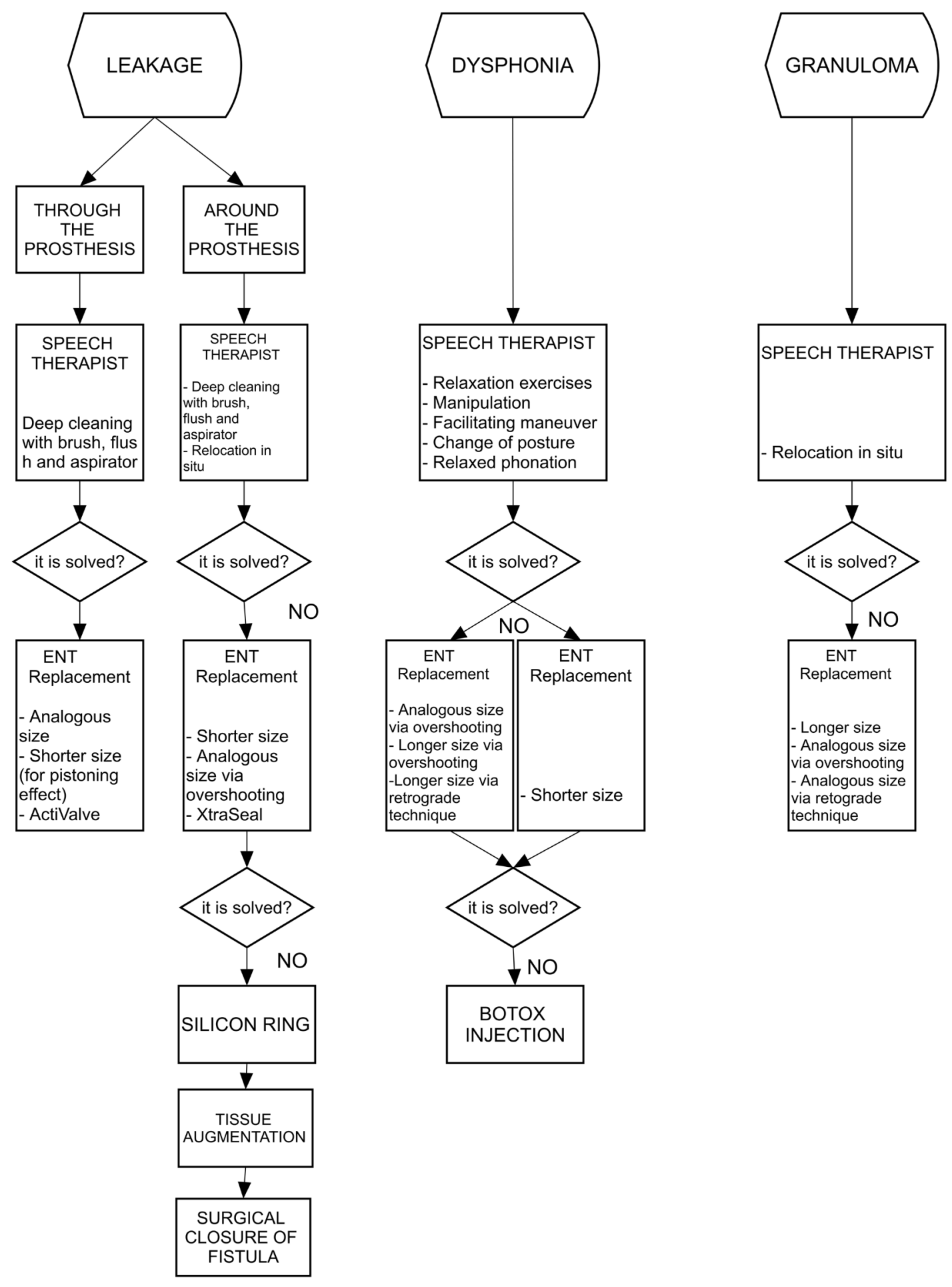

Figure 1. Trouble-shooting algorithm for complications of tracheo-oesophageal prostheses.

Our results show that it is important to verify the status of the prosthetic device at each outpatient evaluation, and, if there are any problems, to establish their exact nature, determine the indication for replacement (leakage through or around, infection of the fistula tract, etc.) and determine the required length of the new prosthesis.

Specifically, when an intravalvular leakage (the most frequent issue) occurred, an analogous prosthesis is the 
solution in most cases ( $70.9 \%$ of cases in our series), because in this specific case we are dealing with a prosthesis-related problem. However, our experience suggested that we should never automatically replace the existing device with another of the same size. In fact, even if the leakage is intravalvular, a different length of prosthesis is sometimes needed. In most of these cases (in our series $22.72 \%$ ), a shorter prosthesis is needed because of shrinkage of the tracheoesophageal wall, otherwise a perivalvular leakage or speaking effort because of the piston effect on the posterior oesophageal wall may be experienced. Rarely (2.72\% in our series), a longer prosthesis can be indicated because of the synchronous presence of hypertrophic/granulation tissue.

When intravalvular leakage occurs too frequently and patients experience a device lifetime of 4 to 8 weeks, or even less ${ }^{26}$, it is necessary to adopt a specialised voice prosthesis equipped with tiny magnets to effectively close the valve, and Candida-resistant material to decrease fungal colonisation ${ }^{27}$ (Provox ActiValve ATOS $^{\circledast}$ Atos Medical $\mathrm{AB}$, Horby, Sweden). This solution was used in our series in only $2.72 \%$ of cases.

According to the literature ${ }^{28}$ and in the present series, the second most common reason for voice prosthesis replacement is peripheral leakage. In these cases, our approach considers the following sequence: downsizing (insertion of a shorter prosthesis); replacement with an analogous prosthesis (same size) via overshooting if leakage is due to dislocation of the oesophageal flange into the wall; extra-flange prosthesis (in our experience the Xtra-seal prosthesis-ATOS ${ }^{\circledR}$ Atos Medical AB, Horby, Sweden); ring application; tissue augmentation (to increase the TEP tract with injectable silicone or autologous fat); surgical closure of the fistula (when required). We intentionally excluded purse string sutures on the fistula tract because in our experience it did not resolve a single case of periprosthetic leakage. In most cases, in fact, it depends on party wall resorption, and therefore the solution is not to shrink it but to augment it. Massive TEP enlargement occurs very seldom, but this adverse event can be a considerable burden on patients and head and neck teams. Some clinicians suggest temporary prosthesis removal allowing the TEP to shrink, but this requires a feeding tube and a cuffed cannula and this is not very appealing to patients. Some authors ${ }^{29}$ suggest that a massive TEP enlargement is the result of a prolonged use of a voice prosthesis that is too long because of its pistoning effect. Precise analysis of this aspect and a proper solution (shorter prosthesis) is the key indication to avoid this troublesome complication.

In cases of effort in voicing due to a hypertonicity or spasm of the pharyngo-oesophageal musculature, confirmed in the diagnostic work-up by a lidocaine test, the solution was
Botulinum toxin injection. We have never used neurectomy of plexus pharingeus and secondary myotomy. In two of 5 patients who underwent botulinum toxin injections, we temporarily resolved the problem and an additional injection was programmed.

Interestingly, in our series, patients who had undergone radiotherapy (preoperative or post-operative) did not show any significant differences from non-irradiated patients in terms of number of accesses to the outpatient clinic or prosthesis lifetime. These data confirm what has already been demonstrated in the literature regarding equivalent late complication rates in the two subgroups of patients ${ }^{30-32}$.

Similarly, no significant differences in the incidence of late complications or management were detected between patients with primary puncture and secondary puncture, according to the literature. In fact, only an intraoperative or early post-operative different rate of complications was demonstrated between the two techniques ${ }^{7-9}$. In particular, major surgery-related complications are described only in secondary punctures. This explains our recent orientation towards primary puncture, reserving secondary punctures for patients from other centres who have failed oesophageal vocal rehabilitation or who are not satisfied with their vocal quality.

Finally, our results showed the central role of the speech therapist in the management of TES patients. In fact, $18.1 \%$ of accesses were resolved exclusively by speech therapists, reducing the number of accesses needing physician treatment/advice, and leading to a significant reduction in costs and time.

Our study highlights the importance of a systematic approach in the management of late complications in voice prosthesis rehabilitated patients. A flow chart with a trouble-shooting algorithm may guide clinicians in the precise detection and adequate treatment.

\section{Conclusions}

The management of late complications is one of the main reasons for the reluctance in using voice prosthesis rehabilitation. Problems occur, despite surgeons' best efforts, as an unavoidable consequence of the presence of a foreign body, represented by the prosthesis. Strict adherence to a tailored trouble-shooting algorithm may offer an easy solution to the most common complications. In a multidisciplinary setting, an initial visit by a speech therapist is useful to render the burden of voice prosthesis management reasonably acceptable for the surgeon, especially in a tertiary referral centre where the high number of patients may become a highly demanding task. 


\section{References}

1 Pawar PV, Sayed SI, Kazi R, et al. Current status and future prospects in prosthetic voice rehabilitation following laryngectomy. J Cancer Res Ther 2008; 4:186-91. https://doi.org/10.4103/0973-1482.44289

2 Ward EC, Koh SK, Frisby J, et al. Differential modes of alaryngeal communication following pharyngolaryngectomy and laryngectomy. Folia Phoniatr Logop 2003;51:39-49. https://doi. org/10.1159/000068056

3 Parrilla C, Minni A, Bogaartd H, et al. Pulmonary rehabilitation after total laryngectomy: a multicenter time-series clinical trial evaluating the Provox XtraHME in HME-Naive patients. Ann Otol Rhinol Laryngol 2015;124:706-13. https://doi.org/10.1177/0003489415579219

4 Macri GF, Bogaartd H, Parrilla C, et al. Patients' experiences with HMEs and attachments after total laryngectomy. Head Neck 2013;35:1583-90. https://doi.org/10.1111/coa.12578

5 Malik T, Bruce I, Cherry J. Surgical complications of tracheooesophageal puncture and speech valves. Curr Opin Otolaryngol Head Neck Surg 2007;15:117-22. https://doi.org/10.1097/ MOO.0b013e3280964dc8

6 Silver FM, Gluckman JL, Donegan JO. Operative complications of tracheoesophageal puncture. Laryngoscope 1985;95:1360-2. https:// doi.org/10.1288/00005537-198511000-00013

7 Ruth H, Davis WE, Renner G. Deep neck abscess after tracheoesophageal puncture and insertion of a voice button prosthesis. Otolaryngol Head Neck Surg 1985;93:809-11. https://doi. org/10.1177/019459988509300622

8 Scheuermann K, Delank KW. Perforation of the esophagus with a mediastinal abscess. HNO 2005;53:66-70. https://doi.org/10.1007/ s00106-004-1067-3

9 Kalcioğlu MT, Kizilay A, Saydam L, et al. A report of four cases of acute mediastinitis occurring following tracheoesophageal puncture in laryngectomees. Kulak Burun Bogaz Ihtis Derg 2004;13:31-4.

10 Bolzoni A, Peretti G, Piazza C, et al. Cervical spondylodiscitis: a rare complication after phonatory prosthesis insertion. Head Neck 2006;28:89-93. https://doi.org/10.1002/hed.20311

11 Albirmawy OA, Elsheikh MN, Saafan ME, et al. Managing problems with tracheoesophageal puncture for a laryngeal voice rehabilitation. J Laryngol Otol 2006;120:470-7. https://doi.org/10.1017/ S0022215106000752

12 Brasnu D, Pages JC, Laccourreye O, et al. Results of the treatment of spontaneous widening of tracheoesophageal punctures after laryngeal implant. Ann Otolaryngol Chir Cervicofac 1994;111:456-60.

13 Hilgers FJ, Ackerstaff AH, Jacobi I, et al. Prospective clinical phase II study of two new indwelling voice prostheses (Provox Vega 22.5 and 20 Fr) and a novel anterograde insertion device (Provox Smart Inserter). Laryngoscope 2010;120:1135-43. https://doi.org/10.1002/lary.20925

14 Lorenz KJ, Maier $\mathrm{H}$. Voice rehabilitation after laryngectomy. Initial clinical experience with the Provox Vega voice prosthesis and the Smart Inserter system. HNO 2010;58:1174-83. https://doi. org/10.1007/s00106-010-2169-8

15 Op de Coul BM, Hilgers FJ, Balm AJ, et al. A decade of post laryngectomy vocal rehabilitation in 318 patients: a single institutions' experience with consistent application of Provox indwelling voice prosthesis. Arch Otolaryngol Head Neck Surg 2000;126:1320-8. https://doi.org/10.1001/archotol.126.11.1320

16 Laccourreye O, Ménard M, Crevier-Buchman C, et al. In situ lifetime, causes for replacement, and complications of the Provox TM voice prosthesis. Laryngoscope 1997;107:527-30. https://doi. org/10.1097/00005537-199704000-00018
17 Van der Molena L, Kornmana AF, Latensteina MN, et al. Practice of laryngectomy rehabilitation interventions: a perspective from Europe/the Netherlands. Curr Opin Otolaryngol Head Neck Surg 2013;21:230-8. https://doi.org/10.1097/MOO.0b013e3283610060

18 Hilgers FJ, Soolsma J, Ackerstaff AH, et al. A thin tracheal silicone washer to solve periprosthetic leakage in laryngectomies: direct results and long-term clinical effects. Laryngoscope 2008;118:640-5. https://doi.org/10.1097/MLG.0b013e31816067d5

19 Jacobs K, Delaere PR, Vander Poorten VL. Submucosal purse-string suture as a treatment of leakage around the indwelling voice prosthesis. Head Neck 2008;30:485-91. https://doi.org/10.1002/hed.20732

20 RokadeAV, Mathews J, Reddy KT. Tissue augmentation using Bioplastique as a treatment of leakage around a Provox 2 voice prosthesis. J Laryngol Otol 2003;117:80-2. https://doi.org/10.1258/002221503321046739

21 Laccourreye O, Papon JF, Brasnu D, et al. Autogenous fat injection for the incontinent tracheoesophageal puncture site. Laryngoscope 2002;112:1512-4. https://doi.org/10.1097/00005537-200208000-00034

22 Hoffman HT, Fischer H, Van Demark D, et al. Botulinum neurotoxin injection after total laryngectomy. Head Neck 1997;19:92-7. https://doi. org/10.1002/(sici)1097-0347(199703)19:2<92::aid-hed2>3.0.co;2-p

23 Singer MI, Blom ED. Selective miotomy for voice restoration after total laryngectomy. Arch Otolaryngol Head Neck Surg 1981;107:6703. https://doi.org/10.1001/archotol.1981.00790470018005

24 D'Alatri L, Bussu F, Scarano E, et al. Objective and subjective assessment of tracheoesophageal prosthesis voice outcome. J Voice 2012;26:607-13. https://doi.org/10.1016/j.jvoice.2011.08.013

25 Longobardi Y, Savoia V, Bussu F, et al. Integrated rehabilitation after total laryngectomy: a pilot trial study. Support Care Cancer 2019;27:3537-44. https://doi.org/10.1007/s00520-019-4647-1

26 Galli J, Calo L, Meucci D, et al. Biofilm in voice prosthesis: a prospective cohort study and laboratory tests using sonication and SEM analysis. Clin Otolaryngol 2018;43:1260-5. https://doi. org/10.1111/coa.13141

27 Soolsma J, van den Brekel MW, Ackerstaff AH, et al. Long-term results of Provox ActiValve, solving the problem of frequent candida- and 'underpressure'- related voice prosthesis replacements. Laryngoscope 2008;118:252-7. https://doi.org/10.1097/MLG.0b013e318159ebde

28 Lorenz KJ. The development and treatment of periprosthetic leakage after prosthetic voice restoration. A literature review and personal experience part I: the development of periprosthetic leakage. Eur Arch Otorhinolaryngol 2015;272:641-59. https://doi.org/10.1007/s00405014-3394-7

29 Hutcheson KA, Lewin JS, Sturgis EM, et al. Enlarged tracheoesophageal puncture after total laryngectomy: a systematic review and meta-analysis. Head Neck 2011;33:20-30. https://doi.org/10.1002/ hed.21399

30 Kao WW, Mohr RM, Kimmel CA, et al. The outcome and techniques of primary and secondary tracheoesophageal puncture. Arch Otolaryngol Head Neck Surg 1994;120:301-7. https://doi. org/10.1001/archotol.1994.01880270047009

31 Galli A, Giordano L, Biafora M, et al. Voice prosthesis rehabilitation after total laryngectomy: are satisfaction and quality of life maintained over time? Acta Otorhinolaryngol Ital 2019;39:162-8. https://doi. org/10.14639/0392-100X-2227

32 Longobardi Y, Galli J, D’Alatri L, et al. Patients with voice prosthesis rehabilitation during the COVID-19 pandemic: analyzing the effectiveness of remote triage and management. Otolaryngol Head Neck Surg 2020 Aug 4;194599820948043 [online ahead of print]. https://doi.org/10.1177/0194599820948043 